\title{
Influence of mitral valve repair versus replacement on the development of late functional tricuspid regurgitation
}

\author{
Bijoy G. Rajbanshi, MBBS, ${ }^{a}$ Rakesh M. Suri, MD, DPhil, ${ }^{a}$ Vuyisile T. Nkomo, MD, MPH, ${ }^{b}$

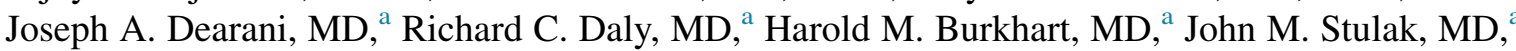 \\ Lyle D. Joyce, MD, PhD, ${ }^{a}$ Zhuo Li, MS, ${ }^{c}$ and Hartzell V. Schaff, $\mathrm{MD}^{\mathrm{a}}$
}

\begin{abstract}
Objectives: To study the determinants of functional tricuspid regurgitation (TR) progression after surgical correction of mitral regurgitation, including the influence of mitral valve (MV) repair (MVr) versus replacement (MVR) for degenerative mitral regurgitation.
\end{abstract}

\begin{abstract}
Methods: From January 1995 to January 2006, 747 adults with MV prolapse underwent isolated MVr ( $\mathrm{n}=683$ ) or MVR $(\mathrm{n}=64$; mechanical in 32$)$. The mean age was 60.8 years, and 491 were men $(66.0 \%)$. Moderate preoperative functional TR was present in $115(15.4 \%)$. The MVR group had a greater likelihood of New York Heart Association class III or IV $(75.0 \%$ vs $34.4 \%, P<.001)$, atrial fibrillation $(20.3 \%$ vs $8.3 \%$, $P=.002)$, a lower left ventricular ejection fraction $(61.0 \%$ vs $65.2 \%, P<.003)$, and a higher pulmonary artery pressure (50.1 vs $41.2 \mathrm{~mm} \mathrm{Hg}, P=.001)$. The patients were monitored for a mean of 6.9 years (MVr) or 7.7 years $(\mathrm{MVR} ; P=.075)$.

Results: During late follow-up, no difference was found between the groups in the development of moderately severe or severe TR: 1 to 5 years $(3.0 \%$ vs $3.3 \%, P=.91)$ and $>5$ years $(6.1 \%$ vs $6.5 \% ; P=.93)$. The univariate predictors of severe TR after 5 years were older age (hazard ratio [HR], 1.1; $P=.011)$, female gender (HR, 6.86; $P=.005)$, higher pulmonary artery pressure (HR, $1.05 ; P=.022)$, and larger left atrial size (HR, $2.11 ; P=.035)$. Two patients $(0.26 \%)$ who had undergone initial MVr required reoperation for late functional TR. Another 2 patients had had the tricuspid valve addressed concurrent with reoperation for MVr failure. No tricuspid reoperations were required in the MVR group.
\end{abstract}

Conclusions: The risk of TR progression was low after MVr or MVR for MV prolapse. Timely MV surgery before the development of left atrial dilatation or pulmonary hypertension could further decrease the risk of TR progression during follow-up. (J Thorac Cardiovasc Surg 2014;148:1957-62)

See related commentary on pages 1962-4.

Tricuspid valve (TV) regurgitation may occur either from a primary anatomic abnormality of the TV apparatus or, more commonly, secondary to annular dilatation (functional) associated with left-sided heart valve disease. Functional TV regurgitation (TR) is often dynamic and can vary with both pulmonary artery pressure and left sided heart valve pathologic features. ${ }^{1}$

\footnotetext{
From the Divisions of Cardiovascular Surgery, ${ }^{\mathrm{a}}$ Cardiovascular Disease, ${ }^{\mathrm{b}}$ and Biomedical Statistics and Informatics, ${ }^{\mathrm{c}}$ Mayo Clinic, Rochester, Minn.

Disclosures: Rakesh M. Suri reports consulting work on the Sorin Percival trial and work as a Co-PI on the Abbott COAPT trial, as well as grant funding from Edwards, Sorin, and St. Jude. Richard C. Daly reports consulting fees for and equity onwership in NeoChord, Inc. All other authors have nothing to disclose with regard to commercial support.

Received for publication Sept 13, 2013; revisions received April 12, 2014; accepted for publication April 18, 2014; available ahead of print May 24, 2014.

Address for reprints: Rakesh M. Suri, MD, DPhil, Division of Cardiovascular Surgery, Mayo Clinic, 200 First St SW, Rochester, MN 55905 (E-mail: suri. rakesh@mayo.edu).

$0022-5223 / \$ 36.00$

Copyright $(2014$ by The American Association for Thoracic Surgery

http://dx.doi.org/10.1016/j.jtcvs.2014.04.041
}

The concomitant correction of moderately severe or severe TR at mitral valve (MV) surgery is most always performed and is well supported by the contemporary evidence. ${ }^{2-5}$ In contrast, asymptomatic moderate or less functional TR associated with left-sided heart disease in the setting of a normal right ventricular (RV) size and function may, at times, stabilize or regress after correction of left-sided heart pathologic entities. Thus, whether the TV should be addressed in such situations has remained controversial. $^{6,7}$ The debate has centered, in part, around the theoretical concern of the risk of delayed progression of TR after isolated correction of mitral regurgitation (MR) necessitating high-risk surgical re-intervention. Despite the existence of strongly held beliefs on this topic longterm studies of a homogeneous population of patients with degenerative MR have been lacking. ${ }^{1,5,8-11}$ It has also been unclear whether MV repair (MVr) or replacement (MVR) influences the likelihood of late TR progression. We, thus, sought to study the progression and late outcomes of preoperatively identified functional TR after surgical correction of MV prolapse. Our aim was to test the null hypothesis that moderate or less functional TR always progresses, necessitating reoperation, and is influenced by the performance of MVr versus MVR. 


$$
\begin{aligned}
& \text { Abbreviations and Acronyms } \\
& \mathrm{HR}=\text { hazard ratio } \\
& \mathrm{LA}=\text { left atrial } \\
& \mathrm{MR}=\text { mitral regurgitation } \\
& \mathrm{MV}=\text { mitral valve } \\
& \mathrm{MVr}=\text { mitral valve repair } \\
& \mathrm{MVR}=\text { mitral valve replacement } \\
& \mathrm{RA}=\text { right atrial } \\
& \mathrm{RV}=\text { right ventricular } \\
& \mathrm{TR}=\text { tricuspid regurgitation } \\
& \mathrm{TV}=\text { tricuspid valve }
\end{aligned}
$$

\section{METHODS}

Patients undergoing surgical correction of isolated myxomatous MR (all caused by degenerative leaflet prolapse) from January 1995 to January 1, 2006 at the Mayo Clinic (Rochester, Minn) were studied, after review and approval from the Mayo Clinic institutional review board. A total of 747 patients $>18$ years old had undergone isolated surgical correction of MR due to degenerative leaflet prolapse using either MVr or MVR. Patients with primary TV disease, right-sided heart failure symptoms, previous TV intervention, or nondegenerative mitral pathologic entities (ie, rheumatic, ischemic, congenital, radiation-induced, pericardial constriction) were excluded from the present study because they had most frequently undergone concomitant TV repair. During the same period, 302 patients had undergone MVR plus TV repair and were not included in the present analysis. Our institutional indications for TV interventions concurrent with degenerative MVR are as follows:

1. Moderately severe or severe TR

2. Right-sided heart failure symptoms with moderate or severe TR

3. Moderate TR with one of the following: primary TV disease, structural abnormalities of the TV (including impingement of the tricuspid leaflets by pacemaker leads), a dilated right atrium and right ventricle, severe pulmonary hypertension, or atrial fibrillation

Those patients who had undergone additional procedures aside from patent foramen ovale closure were not included in the present study to avoid the potential influence on TR. Patients requiring placement of a transvenous pacing lead through the TV before the index operation or during the postoperative period were also excluded. The presence of the lead itself and the performance of ventricular pacing can both accentuate TR; thus, our policy has been to more aggressively correct TR in this setting. Patients with primary lung disease were also excluded from the present study.

TR was assessed using transthoracic echocardiography preoperatively and during follow-up to ascertain progression after MV surgery. MR severity was determined by the assessment of the origin of the regurgitant jet, width (vena contracta) of the jet, effective orifice area, and spatial regurgitant jet area in the receiving chamber. The regurgitant jet radius was also measured, using the proximal isovelocity surface area method in some instances. Functional TR was defined as TR without any anatomic abnormality of the TV leaflets or subvalvar apparatus. TR was quantified from the echocardiographic findings as grade 1 (trace), grade 2 (mild), grade 3 (moderate), and grade 4 (moderately severe or severe). The TR data were analyzed preoperatively and during follow-up at 1, 1 to 5 , and after 5 years.

\section{Statistical Analysis}

The descriptive statistics for categorical variables are reported as frequencies and percentages and continuous variables as the mean \pm standard deviation or median and ranges, as appropriate. The categorical variables were compared between the MVR and MVr groups using the chi-square test or Fisher's exact test. Continuous variables were compared using the 2-sample $t$ test or Wilcoxon rank sum test, as appropriate.

The Kaplan-Meier method was used to draw the survival curves and calculate the 5- and 10-year survival statistics. Cox regression models were used to find the univariate and multivariate predictors of survival. The multivariate model included the variables significant on univariate analysis $(P<.05)$, with model selection using the stepwise method (backward and forward methods resulted in the same model). Univariate logistic regression models were used to find the univariate predictors for the occurrence of TR grade 4 at 1 to 5 years and $\geq 5$ years of follow-up. All statistical tests were 2-sided, with the $\alpha$ level set at 0.05 for statistical significance.

\section{RESULTS \\ Baseline Characteristics}

A total of 683 patients $(91.4 \%)$ underwent $\mathrm{MVr}$ and 64 $(8.6 \%)$ had MVR. Of the 747 patients, 491 were male $(66.0 \%)$ and 256 were female $(34.0 \%)$. The preoperative demographics are listed in Table 1. Slight differences were found between the 2 groups, with the MVR patients older $(65.7 \pm 13.4$ vs $60.4 \pm 13.7$ years, $P=.002)$ and more likely to have New York Heart Association class III or IV symptoms $(75.0 \%$ vs $34.4 \%, P<.001)$, atrial fibrillation $(20.3 \%$ vs $8.3 \%, P=.002)$, a lower left ventricular ejection fraction $(61.0 \% \pm 10 \%$ vs $65.2 \% \pm 8 \%$, $P=.003$ ), and a higher pulmonary artery pressure $(50.1 \pm 19$ vs $41.2 \pm 14 \mathrm{~mm} \mathrm{Hg}, P=.001)$.

\section{Operative Characteristics}

$\mathrm{MVr}$ was performed using conventional valvuloplasty techniques (Table 2). All patients had a standard length posterior annuloplasty band placed during MVr. The MVR group had a mechanical valve placed in 32 patients $(50.0 \%)$. MVr had initially been attempted in 15 patients $(23.0 \%)$ in the MVR group within this historic series.

\section{Early Complications and Late Survival}

The early complications are listed in Table 2 . There were 4 early deaths $(0.6 \%)$ after MVr and $1(1.6 \%)$ after MVR $(P=.362)$. The patients were followed up for mean period of $7.0 \pm 3.9$ years $(\mathrm{MVr}, 6.9 \pm 3.9$ years; MVR, $7.7 \pm 3.8$ years; $P=.075)$.

\section{Presence of Postoperative Moderately Severe or Severe Symptomatic TR and Surgical Intervention}

The presence of moderately severe or severe TR was assessed at 1,1 to 5 , and after 5 years (Table 3). The completeness of echocardiographic follow-up for the patients at risk at these periods was 238 of 673 patients $(35.4 \%)$ at $<1$ year, 275 of 564 patients $(48.8 \%)$ at 1 to 5 years, and 200 of 249 patients $(80.3 \%)$ at $>5$ years. During the follow-up period, the incidence of grade IV TR was similarly low among the MVr and MVR groups at $<1$ year $(2.5 \%$ vs $7.7 \%, P=.264), 1$ to 5 years $(3.0 \%$ vs $3.3 \%, P=.915)$, and $>5$ years $(6.1 \%$ vs $6.5 \%, P=.934)$. 
TABLE 1. Patient characteristics

\begin{tabular}{|c|c|c|c|c|}
\hline Characteristic & $\begin{array}{c}\text { All } \\
\text { patients }\end{array}$ & $\begin{array}{c}\text { MVr } \\
(n=683)\end{array}$ & $\begin{array}{c}\text { MVR } \\
(n=64)\end{array}$ & $\begin{array}{c}P \\
\text { value }\end{array}$ \\
\hline Age (y) & $60.8 \pm 13.7$ & $60.4 \pm 13.7$ & $65.7 \pm 13.4$ & \\
\hline \multicolumn{5}{|l|}{ Gender } \\
\hline Male & $491(66)$ & $450(65.9)$ & $41(64.1)$ & \\
\hline Female & $256(34)$ & $233(34.1)$ & $23(35.9)$ & \\
\hline \multicolumn{4}{|l|}{ NYHA class } & \\
\hline I and II & $464(62.1)$ & 448 (65.6) & $16(25)$ & \\
\hline III and IV & 283 (37.9) & $235(34.4)$ & $48(75)$ & \\
\hline Hypertension & $288(39)$ & $270(39.5)$ & $18(28.1)$ & \\
\hline Diabetes & $19(3)$ & $18(2.6)$ & $1(1.6)$ & \\
\hline $\begin{array}{l}\text { Preoperative atrial } \\
\text { fibrillation }\end{array}$ & $70(9)$ & $57(8.3)$ & $13(20.3)$ & \\
\hline $\mathrm{EF}(\%)$ & $64.9 \pm 7.8$ & $65.2 \pm 7.6$ & $61.0 \pm 9.8$ & .0 \\
\hline LVEDD (mm) & $57.8 \pm 7.1$ & $58.1 \pm 6.3$ & $53.0 \pm 15.1$ & \\
\hline LVESD (mm) & $35.3 \pm 7.1$ & $35.4 \pm 5.9$ & $32.8 \pm 11.5$ & .8 \\
\hline MR & & - & - & - \\
\hline Grade III & $50(7)$ & & & \\
\hline Grade IV & 697 (93) & & & \\
\hline \multicolumn{5}{|l|}{ Preoperative TR } \\
\hline Grade I and II & $598(80.0)$ & $570(83.5)$ & $28(43.8)$ & \\
\hline Grade III & $115(15.4)$ & $110(16.1)$ & $5(7.8)$ & \\
\hline No TR & 34 (4.6) & $3(0.4)$ & $31(48.4)$ & \\
\hline $\operatorname{RVSP}(\mathrm{mm} \mathrm{Hg})$ & $41.75 \pm 14.8$ & $41.2 \pm 14.3$ & $50.1 \pm 18.6$ & 0 \\
\hline
\end{tabular}

Data presented as mean \pm standard deviation or $\mathrm{n}(\%) . M V r$, Mitral valve repair; $M V R$, mitral valve replacement; $N Y H A$, New York Heart Association; $E F$, ejection fraction; $L V E D D$, left ventricular end-diastolic dimension; $L V E S D$, left ventricular end-systolic dimension; $M R$, mitral regurgitation; $R V S P$, right ventricular systolic pressure; $T R$, tricuspid regurgitation.

We addressed the TV during our follow-up period in 4 patients. Two patients required isolated TV replacement, one at 4 years and one at 14 years after MVr. Two patients had the TV addressed at the time of MV reoperation.

The recurrence of MR was low and similar between the 2 groups (Table 3). The prevalence of heart failure symptoms was greater in the MVR group up to the 5-year follow-up point. After 5 years, the incidence of heart failure symptoms was similar in both groups $(1.9 \%$ vs $3.7 \%, P=.544)$. The predictors of the presence of grade IV functional TR at 1 to 5 years and after 5 years are listed in Table 4 and included advanced age $(P=.011)$, female gender $(P=.005)$, elevated pulmonary pressure $(P=.022)$, and increased left atrial (LA) size $(P=.035)$. MVR was not a statistically significant univariate predictor for progression of functional TR at any point during the follow-up period. Patients with preoperative atrial fibrillation were 4.58 times more likely to experience TR progression late after $\mathrm{MVr}$; however, this did not reach statistical significance in the present analysis $(P=.054)$. None of these factors were significant independent predictors on multivariate analysis of late TR during follow-up at 1 to 5 or after 5 years.

\section{DISCUSSION}

Functional TR has been shown to exist in $\leq 30 \%$ of patients undergoing isolated MV surgery. ${ }^{4,8}$ In our study,
TABLE 2. Intraoperative and postoperative characteristics

\begin{tabular}{|c|c|c|}
\hline Variable & Value & $P$ value \\
\hline \multicolumn{3}{|l|}{$\mathrm{MVr}$} \\
\hline Posterior leaflet resection & 496 (70.6) & \\
\hline Chordae transfer & $32(4.7)$ & \\
\hline Artificial chordae & $104(15.2)$ & \\
\hline Edge to edge repair & $17(2.5)$ & \\
\hline \multicolumn{3}{|l|}{ MVR } \\
\hline Tissue valve & $32(50.0)$ & \\
\hline Mechanical valve & $32(50.0)$ & \\
\hline Repair attempted & $15(24.0)$ & \\
\hline Approach, sternotomy & & - \\
\hline MVr & $675(98.8)$ & \\
\hline MVR & $64(100)$ & \\
\hline Minimally invasive approach, minithoracotomy & & - \\
\hline $\mathrm{MVr}$ & $8(1.2)$ & \\
\hline MVR & $0(0)$ & \\
\hline Aortic crossclamp time (min) & & $<.001$ \\
\hline $\mathrm{MVr}$ & $36.2 \pm 16.5$ & \\
\hline MVR & $63.6 \pm 25.3$ & \\
\hline Extracorporeal circulation time (min) & & $<.001$ \\
\hline $\mathrm{MVr}$ & $51.6 \pm 24.9$ & \\
\hline MVR & $92.9 \pm 37.8$ & \\
\hline PFO closure & & - \\
\hline $\mathrm{MVr}$ & $87(12.7)$ & \\
\hline MVR & $5(7.8)$ & \\
\hline Postoperative AF & & $<.001$ \\
\hline $\mathrm{MVr}$ & 327 (47.9) & \\
\hline MVR & $15(23.4)$ & \\
\hline Re-exploration for bleeding & & .206 \\
\hline $\mathrm{MVr}$ & $22(3.2)$ & \\
\hline MVR & $4(6.3)$ & \\
\hline Early mortality & & .362 \\
\hline $\mathrm{MVr}$ & $4(0.6)$ & \\
\hline MVR & $1(1.6)$ & \\
\hline Stroke & & 612 \\
\hline $\mathrm{MVr}$ & $11(1.6)$ & \\
\hline MVR & $0(0)$ & \\
\hline PPM & & .362 \\
\hline $\mathrm{MVr}$ & $4(0.6)$ & \\
\hline MVR & $1(1.6)$ & \\
\hline Renal dysfunction & & .075 \\
\hline $\mathrm{MVr}$ & $9(1.3)$ & \\
\hline MVR & $3(4.7)$ & \\
\hline
\end{tabular}

Data presented as mean \pm standard deviation or $\mathrm{n}(\%) . M V r$, Mitral valve repair $M V R$, mitral valve replacement; $P F O$, patent foramen ovale; $A F$, atrial fibrillation $P P M$, permanent pacemaker.

most patients with degenerative MV prolapse had minimal or no TR while 115 patients $(15 \%)$ had more than mild TR at index mitral operation. Importantly, no difference was found in the development of moderately severe or severe TR or heart failure symptoms after 5 years despite a decision not to address moderate-or-less TR. We found that the unadjusted predictors of TR progression after 5 years were older age, female gender, higher preoperative pulmonary artery pressure, and larger LA size. Taken 
TABLE 3. Comparison of postoperative presence of MR, TR, and symptoms between MVr and MVR

\begin{tabular}{lccc}
\hline \multicolumn{1}{c}{ Follow-up point } & MVr & MVR & P value \\
\hline$<1$ y & & & \\
MR grade I-III & $220(98.7)$ & $12(100)$ & .686 \\
MR grade IV & $3(1.3)$ & $0(0)$ & \\
TR grade I-III & $199(97.6)$ & $12(92.3)$ & .264 \\
TR grade IV & $5(2.5)$ & $1(7.7)$ & \\
NYHA class I and II & $55(98.2)$ & $13(86.7)$ & .048 \\
NYHA class III and IV & $1(1.8)$ & $2(13.3)$ & \\
1-5 y & & & \\
MR grade I-III & $241(98.4)$ & $26(96.3)$ & .447 \\
MR grade IV & $4(1.6)$ & $1(3.7)$ & \\
TR grade I-III & $228(97.0)$ & $29(96.7)$ & .915 \\
TR grade IV & $7(3.0)$ & $1(3.3)$ & \\
NYHA class I and II & $82(98.8)$ & $27(90)$ & .026 \\
NYHA class III and IV & $1(1.2)$ & $3(10)$ & \\
$>5$ y & & & \\
MR grade I-III & $165(97.6)$ & $23(100)$ & .456 \\
MR grade IV & $4(2.4)$ & $0(0)$ & \\
TR grade I-III & $155(93.9)$ & $29(93.5)$ & .934 \\
TR grade IV & $10(6.1)$ & $2(6.5)$ & \\
NYHA class I and II & $157(98.1)$ & $26(96.3)$ & .544 \\
NYHA class III and IV & $3(1.9)$ & $1(3.7)$ & \\
\hline
\end{tabular}

Data presented as n (\%). $M R$, Mitral regurgitation; $T R$, tricuspid regurgitation; $M V r$, mitral valve repair; $M V R$, mitral valve replacement; NYHA, New York Heart Association.

together, these data suggest that the timing of MVr for severe chronic degenerative MR could possibly be influential in the progression of moderate or less functional TR, identified at surgical correction of severe degenerative MR. Definitive conclusions will necessarily await the incorporation of additional markers of chronicity in future analyses, to determine which are most influential in avoiding the onset and progression of functional TR.

Conflicting data have been published regarding the progression of uncorrected moderate-or-less TR, varying from minor to significant consequences on morbidity and mortality. Those opting not to correct functional TR have inferred that annular dilatation and RV enlargement might eventually regress over time after correction of left-sided heart pathologic entities, ${ }^{6,7}$ but others have related that delayed progression of TR might adversely effect late patient survival. ${ }^{2,5,9}$ Nath and colleagues ${ }^{9}$ demonstrated that the 1-year survival of patients will be adversely affected is impacted by the presence and severity of TR, which has led to renewed interest in the correction of moderate TR at MV surgery. ${ }^{2,4}$

Although the progression of TR has been documented for patients with rheumatic mitral disease ${ }^{12}$ and those with ischemic mitral valve pathology, ${ }^{13}$ this might not hold true for all MV disease etiologies. Yilmaz and colleagues, ${ }^{14}$ in a review of patients with degenerative MV disease who had undergone $\mathrm{MVr}$ from our institution did not find that
TABLE 4. Risk factors for development of late grade IV tricuspid regurgitation

\begin{tabular}{|c|c|c|c|c|}
\hline \multirow[b]{2}{*}{ Risk factor } & \multicolumn{2}{|l|}{$1-5 y$} & \multicolumn{2}{|l|}{$>5 \mathrm{y}$} \\
\hline & HR $(95 \%$ CI $)$ & $\begin{array}{c}P \\
\text { value }\end{array}$ & HR $(95 \%$ CI $)$ & $\begin{array}{c}P \\
\text { value }\end{array}$ \\
\hline Age & $1.12(1.02-1.22)$ & .017 & $1.1(1.02-1.17)$ & .011 \\
\hline Female gender & $2.34(0.57-9.59)$ & .24 & $6.86(1.79-26.29)$ & .005 \\
\hline Preoperative AF & $2.43(0.47-12.57)$ & .29 & $4.58(0.98-21.48)$ & .054 \\
\hline $\begin{array}{l}\text { Preoperative TR } \\
\text { grade }>2\end{array}$ & $14.63(2.85-75.08)$ & .001 & $2.74(0.75-9.97)$ & .130 \\
\hline Preoperative EF & $0.93(0.87-1)$ & .041 & $1(0.93-1.07)$ & .990 \\
\hline Preoperative RVSP & $1.04(1.01-1.08)$ & .017 & $1.05(1.01-1.09)$ & .022 \\
\hline Preoperative RA size & $2.06(0.97-4.38)$ & .06 & $1.53(0.84-2.79)$ & .160 \\
\hline Preoperative LA size & $1.25(0.59-2.62)$ & .56 & $2.11(1.05-4.21)$ & .035 \\
\hline Preoperative RV size & NA & NA & $3.75(0.9-15.66)$ & .070 \\
\hline MVR & $1.12(0.13-9.46)$ & .915 & $1.07(0.22-5.13)$ & .934 \\
\hline
\end{tabular}

$H R$, Hazard ratio; $C I$, confidence interval; $A F$, atrial fibrillation; $T R$, tricuspid regurgitation; $E F$, ejection fraction; $R V S P$, right ventricular systolic pressure; $R A$, right atrial; $L A$, left atrial; $R V$, right ventricular; $N A$, not applicable; $M V R$, mitral valve replacement.

significant TR progression occurred after surgery in this specific population. Only 1 patient required surgical TR correction during the follow-up period. We hypothesized that patients with MV leaflet prolapse might be more likely to undergo earlier MVr, thus avoiding the development of severe distortion of the RV geometry that appears etiologic in the insidious and irreversible progression of functional TR. ${ }^{14}$ Supporting this hypothesis, Benedetto and colleagues ${ }^{15}$ did not find a statistically significant advantage for TV annuloplasty in patients with degenerative MV disease, although TV repair provided a benefit in those with rheumatic and ischemic MV pathologic features.

We believe that the role of MV disease etiology in the progression of TR might be underappreciated and might be more influential in the progression of TR after MV surgery. Most published studies reporting TR progression after MV surgery have either studied functional TR in heterogeneous categories of patients (rheumatic, ischemic, radiation-induced, congenital, inflammatory) or have failed to stratify by etiology. $2,8,12,13,15-17$ That we studied a homogenous group of patients with degenerative MR is unique and entails that the results are directly applicable to a large population of patients presenting for early mitral valve surgery in contemporary cardiac surgical practice.

The factors known to result in the persistence or progression of TR are age, ${ }^{3,8,18-20}$ female gender, ${ }^{3,14,18}$ preoperative left ventricular and RV function, ${ }^{8,16,20}$ and atrial fibrillation. ${ }^{4,14,16,20,21}$ Atrial fibrillation has long been recognized as an important predictor of the development of TR. ${ }^{4,14,16}$ Enlarged left and right atria predispose to atrial fibrillation and, in turn, could influence the development of tricuspid incompetence. ${ }^{16,22}$ In the present study, although a trend was seen for 
preoperative atrial fibrillation to predict the development of postoperative TR (hazard ratio [HR], 2.43 and $P=.29$ at 1-5 years; HR, 4.58 and $P=.054$ at $>5$ years), it did not reach statistical significance, which we have previously demonstrated. ${ }^{14,23}$ We also assessed the LA, right atrial (RA), and RV size as risks of TR progression. Although the preoperative LA size was a significant predictor at $>5$ years (HR, 2.11; $P=.035$ ), none of the other factors appeared to be influential, although an enlarged RA size was close to statistical significance for TR progression at 1 to 5 years $(\mathrm{HR}, 2.06 ; P=.06)$ and $>5$ years $(\mathrm{HR}, 3.75$; $P=.07) . \mathrm{He}$ and colleagues ${ }^{22}$ have suggested repair of functional TR when the right atrium and ventricle are dilated. They recommended addressing the TV when the RA diameter is $>57 \mathrm{~mm}$, the RV end-systolic diameter is $>55 \mathrm{~mm}$, and pulmonary artery pressure is $>58 \mathrm{~mm} \mathrm{Hg}$. Our study was not designed to test this recommendation.

It is difficult to predict which patients will develop progression or regression of functional TR following successful elimation of severe degenerative MR. Repair of moderate functional TR is an American College of Cardiology/American Heart Association guideline class IIB recommendation when associated with pulmonary hypertension or annular dilatation (level of evidence C); it is a class IIA indication in the presence of a dilated annulus as a concomitant procedure according to the European Society of Cardiology guidelines. ${ }^{24,25}$ Various investigators have advocated TV repair when annular dilatation is present. ${ }^{15,19,21}$ Groves and colleagues ${ }^{26}$ suggested that once the annulus has become enlarged, a minimal further increase will be associated with significant TR progression. Thus, treating the MV lesion alone in such patients will only reduce the afterload and will not necessarily alter $\mathrm{TV}$ annular dilatation or improve RV function and, thus, would not eliminate the substrate for TR persistence or progression. ${ }^{4}$ Although we did not historically measure the TV annular dimension, patients were included in our present study if they had normal RV size and function. The derived conclusions will thus be applicable to this specific population of patients.

The limitations of the present study were consistent with its retrospective nature. A prospective randomized study would not be plausible, because MVr continues to be the preferred procedure over MVR. Also, recent evidence has confirmed that early $\mathrm{MVr}$ in the absence of symptoms improves long-term survival. ${ }^{27}$ Although we monitored TR on clinically indicated echocardiograms, it is possible that those with significant TR evaded detection. However, this possibility was unlikely owing to the typically robust follow-up in our referral network and that right-sided heart failure associated with severe TR typically detected on physical examination depite the fact that symptoms may be more difficult to quantify. Also, the patients seen in follow-up at our valvular heart disease clinics have echocardiograms readily available, and assessment of both left- and right-sided heart function is routinely performed.

\section{CONCLUSIONS}

Our results have shown that moderate or less TR in patients undergoing isolated surgical correction of degenerative MR is unlikely to progress in the absence of symptoms, concomitant cardiac disease, right-sided heart failure, an increased LA size, or pulmonary hypertension. The risk of TR progression was similarly low after either MVr or MVR in this historic series. Age, gender, and the timing of MV surgery could all potentially influence the progression of functional TR; however, definitive conclusions will necessarily await the incorporation of additional markers of chronicity in future analyses. A thoughtful, individualized approach based upon available evidence relevant to specific disease-based population being discussed, remains essential in deciding when correction of moderate-or-less functional TR is required.

\section{References}

1. Messika-Zeitoun D, Thomson H, Bellamy M, Scott C, Tribouilloy C, Dearani J, et al. Medical and surgical outcome of tricuspid regurgitation caused by flail leaflets. J Thorac Cardiovasc Surg. 2004;128:296-302.

2. Calafiore AM, Gallina S, Iaco AL, Contini M, Bivona A, Gagliardi M, et al. Mitral valve surgery for functional mitral regurgitation: should moderate-ormore tricuspid regurgitation be treated? A propensity score analysis. Ann Thorac Surg. 2009;87:698-703.

3. Desai RR, Vargas Abello LM, Klein AL, Marwick TH, Krasuski RA, Ye Y, et al. Tricuspid regurgitation and right ventricular function after mitral valve surgery with or without concomitant tricuspid valve procedure. J Thorac Cardiovasc Surg. 2013;146:1126-32.e10.

4. Anyanwu AC, Chikwe J, Adams DH. Tricuspid valve repair for treatment and prevention of secondary tricuspid regurgitation in patients undergoing mitral valve surgery. Curr Cardiol Rep. 2008;10:110-7.

5. Rogers JH, Bolling SF. The tricuspid valve: current perspective and evolving management of tricuspid regurgitation. Circulation. 2009;119:2718-25.

6. Song JM, Kang DH, Song JK, Jeong YH, Lee CW, Hong MK, et al. Outcome of significant functional tricuspid regurgitation after percutaneous mitral valvuloplasty. Am Heart J. 2003;145:371-6.

7. Braunwald NS, Ross J Jr, Morrow AG. Conservative management of tricuspid regurgitation in patients undergoing mitral valve replacement. Circulation. 1967;35(4 Suppl):I63-9.

8. Chan V, Burwash IG, Lam BK, Auyeung T, Tran A, Mesana TG, et al. Clinical and echocardiographic impact of functional tricuspid regurgitation repair at the time of mitral valve replacement. Ann Thorac Surg. 2009;88:1209-15.

9. Nath J, Foster E, Heidenreich PA. Impact of tricuspid regurgitation on long-term survival. J Am Coll Cardiol. 2004;43:405-9.

10. Anyanwu AC, Adams DH. Functional tricuspid regurgitation in mitral valve disease: epidemiology and prognostic implications. Semin Thorac Cardiovasc Surg. 2010;22:69-75.

11. King RM, Schaff HV, Danielson GK, Gersh BJ, Orszulak TA, Piehler JM, et al Surgery for tricuspid regurgitation late after mitral valve replacement. Circulation. 1984;70(3 Pt 2):I193-7.

12. Matsuyama K, Matsumoto M, Sugita T, Nishizawa J, Tokuda Y, Matsuo T. Predictors of residual tricuspid regurgitation after mitral valve surgery. Ann Thorac Surg. 2003; 75:1826-8.

13. Matsunaga A, Duran CM. Progression of tricuspid regurgitation after repaired functional ischemic mitral regurgitation. Circulation. 2005;112(9 suppl):I453-7.

14. Yilmaz O, Suri RM, Dearani JA, Sundt TM III, Daly RC, Burkhart HM, et al. Functional tricuspid regurgitation at the time of mitral valve repair for degenerative leaflet prolapse: the case for a selective approach. J Thorac Cardiovasc Surg. 2011;142:608-13. 
15. Benedetto U, Melina G, Angeloni E, Refice S, Roscitano A, Comito C, et al. Prophylactic tricuspid annuloplasty in patients with dilated tricuspid annulus undergoing mitral valve surgery. J Thorac Cardiovasc Surg. 2012;143:632-8.

16. Porter A, Shapira Y, Wurzel M, Sulkes J, Vaturi M, Adler Y, et al. Tricuspid regurgitation late after mitral valve replacement: clinical and echocardiographic evaluation. J Heart Valve Dis. 1999:8:57-62.

17. Kim JB, Yoo DG, Kim GS, Song H, Jung SH, Choo SJ, et al. Mild-to-moderate functional tricuspid regurgitation in patients undergoing valve replacement for rheumatic mitral disease: the influence of tricuspid valve repair on clinical and echocardiographic outcomes. Heart. 2012;98:24-30.

18. Taramasso M, Vanermen H, Maisano F, Guidotti A, La Canna G, Alfieri O. The growing clinical importance of secondary tricuspid regurgitation. J Am Coll Cardiol. 2012;59:703-10.

19. Dreyfus GD, Corbi PJ, Chan KM, Bahrami T. Secondary tricuspid regurgitation or dilatation: which should be the criteria for surgical repair? Ann Thorac Surg. 2005;79:127-32.

20. Ro SK, Kim JB, Jung SH, Choo SJ, Chung CH, Lee JW. Mild-to-moderate functional tricuspid regurgitation in patients undergoing mitral valve surgery. J Thorac Cardiovasc Surg. 2013;146:1092-7.

21. Shinn SH, Schaff HV. Evidence-based surgical management of acquired tricuspid valve disease. Nat Rev Cardiol. 2013;10:190-203.

22. He J, Shen Z, Yu Y, Huang H, Ye W, Ding Y, et al. Criteria for determining the need for surgical treatment of tricuspid regurgitation during mitral valve replacement. J Cardiothorac Surg. 2012;7:27.
23. Stulak JM, Schaff HV, Dearani JA, Orszulak TA, Daly RC, Sundt TM III. Restoration of sinus rhythm by the maze procedure halts progression of tricuspid regurgitation after mitral surgery. Ann Thorac Surg. 2008;86:40-4; discussion 4-5.

24. Bonow RO, Carabello BA, Kanu C, de Leon AC Jr, Faxon DP, Freed MD, et al. ACC/AHA 2006 guidelines for the management of patients with valvular heart disease: a report of the American College of Cardiology/American Heart Association Task Force on Practice Guidelines (Writing Committee to revise the 1998 Guidelines for the Management of Patients With Valvular Heart Disease): developed in collaboration with the Society of Cardiovascular Anesthesiologists: endorsed by the Society for Cardiovascular Angiography and Interventions and the Society of Thoracic Surgeons. Circulation. 2006; 114:e84-231.

25. Vahanian A, Baumgartner H, Bax J, Butchart E, Dion R, Filippatos G, et al. Guidelines on the management of valvular heart disease: the Task Force on the Management of Valvular Heart Disease of the European Society of Cardiology. Eur Heart J. 2007;28:230-68.

26. Groves PH, Lewis NP, Ikram S, Maire R, Hall RJ. Reduced exercise capacity in patients with tricuspid regurgitation after successful mitral valve replacement for rheumatic mitral valve disease. Br Heart J. 1991;66: 295-301.

27. Suri RM, Vanoverschelde JL, Grigioni F, Schaff HV, Tribouilloy C, Avierinos JF, et al. Association between early surgical intervention vs watchful waiting and outcomes for mitral regurgitation due to flail mitral valve leaflets. JAMA 2013;310:609-16.

\title{
EDITORIAL COMMENTARY
}

\section{"Forgotten" valve or "enigmatic" valve? Further insights into the tricuspid valve in patients undergoing mitral valve surgery}

\author{
Elizabeth H. Stephens, MD, PhD, and Michael A. Borger, MD, PhD
}

See related article on pages 1957-62.

Commonly referred to as the "forgotten valve," the tricuspid valve (TV) has received increasing attention in recent years. ${ }^{1}$ Functional tricuspid regurgitation (fTR) was often overlooked in the past, both because correction of left-sided valvular pathology was thought to sufficiently ameliorate fTR and because the optimal TV repair technique was unknown. We now know that fTR does not always improve after left-sided surgery and that residual

From the Department of Cardiac, Thoracic, and Vascular Surgery, Columbia University Medical Center, New York, NY.

Disclosures: Authors have nothing to disclose with regard to commercial support. Received for publication Sept 14, 2014; accepted for publication Sept 15, 2014

Address for reprints: Michael A. Borger, MD, PhD, Department of Cardiac, Thoracic, and Vascular Surgery, Columbia University Medical Center, 177 Fort Washington Ave, MHB 7GN-435, New York, NY 10032 (E-mail: mb3851@ cumc.columbia.edu). J Thorac Cardiovasc Surg 2014;148:1962-4 0022-5223/\$36.00

Copyright (C) 2014 by The American Association for Thoracic Surgery http://dx.doi.org/10.1016/j.jtcvs.2014.09.037 tricuspid regurgitation (TR) imparts a poor long-term prognosis. Residual TR is associated with a 2 -fold risk of heart failure $^{1}$ and a $50 \%$ decrease in 5-year survival. ${ }^{2}$ Residual TR is also progressive, with one-half of all patients having progression by more than 2 grades 5 years after surgery. ${ }^{3}$ In addition, isolated TV surgery for TR is associated with unacceptably high morbidity and mortality after mitral valve (MV) surgery. ${ }^{4}$

In light of these findings, some investigators have argued strongly for concomitant TV repair for patients with any amount of fTR - or even for those with isolated tricuspid annular dilation without fTR - when they undergo left-sided valvular surgery. ${ }^{5}$ Several different tricuspid annuloplasty rings have been designed for fTR, with none demonstrating clear clinical superiority to date. Some evidence suggests, however, that flexible rings may be associated with a lower risk of dehiscence relative to rigid rings. ${ }^{6}$ Determining which criteria should be applied to performing TV repair in patients undergoing MV surgery remains a topic of debate.

Current guidelines recommend that severe TR should be addressed at the time of MV surgery, ${ }^{7,8}$ because TV 